\title{
LA TRANSICIÓN DE CAZADORES-RECOLECTORES A SOCIEDADES AGROPASTORILES EN ANTOFAGASTA DE LA SIERRA (PUNA DE CATAMARCA, ARGENTINA): PERSPECTIVAS DESDE LA AGENCIA Y LAS PRÁCTICAS ${ }^{1}$
}

\author{
THE TRANSITION FROM HUNTER-GATHERERS TO AGRO-PASTORALIST \\ SOCIETIES IN ANTOFAGASTA DE LA SIERRA (ARGENTINEAN PUNA, \\ ARGENTINA): PERSPECTIVES FROM AGENCY AND PRACTICES
}

\author{
Salomón Hocsman² y María del Pilar Babot ${ }^{2}$
}

\begin{abstract}
Desarrollamos el contenido y alcances de la noción de transición a la producción de alimentos (TPA) y su aplicación al tránsito de cazadores-recolectores a sociedades agropastoriles en Antofagasta de la Sierra, Puna meridional argentina. Discutimos, en particular, cuestiones relativas a las prácticas culinarias, al asentamiento/emplazamiento de los sitios residenciales y a la emergencia de identidades con especial referencia al lapso 5.000-3.000 cal. a.p. (4.500-3.000 a.p.) y realizamos consideraciones sobre momentos previos y posteriores en el continuo local. Para esto, integramos y revisamos los datos ya existentes para el área, desde el análisis arqueológico de la producción, reproducción y transformación social durante el nodo de la transición, aproximándonos a ello desde la perspectiva de las prácticas y la agencia.
\end{abstract}

Palabras claves: transición a la producción de alimentos, agencia, prácticas culinarias, asentamiento, identidad, Puna Argentina.

In this article, we develop the content and scope of the notion of transition to food production (TFP) and use it to understand the transition from hunter-gatherers to agro-pastoralist societies in Antofagasta de la Sierra, in the southern Puna of Argentina. We particulary focus on, issues related to culinary practices, the settlement / emplacement of residential sites, and the emergence of identities, with special reference to the period between 5,000 and 3,000 cal. BP (4,500-3,000 BP). We also refer to the previous and subsequent moments in the local continuum. To do that, we integrate and review the existing data for the area from the archaeological analysis of the social production, reproduction and transformation during the node of the transition, approaching it from the perspective of practices and agency.

Key words: Transition to food production, agency, culinary practices, settlement, identity, Argentinean Puna.

La transición o tránsito a la producción de alimentos es un tema de interés global, donde el concepto de transición tiene un uso generalizado en trabajos de diferentes perspectivas teóricometodológicas y distintos casos de estudio abarcando variadas áreas geográficas, vestigios arqueológicos y temporalidades (Bruno 2009; Finlayson 2010; Gremillion et al. 2014; Kennett y Winterhalder 2006; Marsh 2015; Pearsall 2009; Price y BarYosef 2011; Robb 2013; Starr 2005; Whittle y Cummings 2007). Entre esas áreas, las tierras altas del Noroeste argentino proveen de una excelente posibilidad de análisis de las trayectorias locales durante la transición entre un modo de vida basado en la caza y recolección a otro productor. Allí se ha generado una importante literatura sobre las particularidades de las secuencias locales en la cronología abarcada por esta transición, siendo abordado el cambio sociocultural desde múltiples perspectivas teóricas y considerando factores culturales, sociales, ideológicos, ambientales y biológicos involucrados en ello (Aschero 2010; López 2013; López y Restifo 2012, 2014; Moreno 2013; Muscio 2001; Ratto 2003; Yacobaccio 1998, 2006; Yacobaccio et al. 1997-98; entre otros). El estudio de la transición en esta región puede aportar a una serie de problemas relevantes para la arqueología contemporánea (Kintigh et al. 2014),

\footnotetext{
1 Una primera versión de este artículo fue presentada en el XIX Congreso Nacional de Arqueología Argentina, Tucumán (agosto 2016), en el marco del simposio "El tránsito de modos de vida cazadores-recolectores a agro-pastoriles en la porción meridional de los Andes Centro-Sur: Trayectorias de continuidad y cambio". Este manuscrito fue evaluado por pares externos y editado por el Comité Editorial de Chungara y los editores invitados Marcela Sepúlveda y Francisco Gallardo.

2 Instituto Superior de Estudios Sociales (ISES), CONICET - Universidad Nacional de Tucumán. Instituto de Arqueología y Museo (IAM), Facultad de Ciencias Naturales e Instituto Miguel Lillo, Universidad Nacional de Tucumán. Saavedra 254 (CP 4.000) San Miguel de Tucumán, Tucumán, Argentina. shocsman@hotmail.com; pilarbabot@yahoo.com
} 
como son: el surgimiento de la producción de alimentos en sociedades cazadoras-recolectoras, en lo que se considera como "ambiente extremo" por su elevada altitud y aridez, entre otros factores (Aldenderfer 1998); la emergencia de comunidades de mayor escala y la conformación de identidades.

En este marco, en este trabajo vamos a: (1) desarrollar el contenido y alcances de la noción de transición a la producción de alimentos aquí empleada; (2) integrar y reevaluar desde la perspectiva de la agencia y de las prácticas la información existente para el lapso y área de estudio, motivo por el cual nos referiremos a trabajos anteriores en donde la información primaria ya ha sido expuesta y discutida in extenso y; (3) plantear perspectivas de trabajo a futuro con respecto al tránsito de cazadores-recolectores a sociedades agropastoriles en el desierto de altura de Antofagasta de la Sierra (Catamarca, Argentina).

Específicamente, abordaremos cuestiones relativas a las prácticas culinarias, al asentamiento/ emplazamiento de los sitios residenciales y a la emergencia de identidades con especial referencia al lapso 5.000-3.000 cal. a.p. (4.500-3.000 a.p.), considerando momentos previos y posteriores en el continuo local. Nos basaremos principalmente en información procedente de un conjunto de sitios estudiados en el área con cronología absoluta (Tabla 1, Figura 1) que han sido caracterizados por Aschero y Hocsman (2011) y en una serie de sitios con cronología relativa reseñados por Hocsman $(2002$, 2006). Para ello, trabajaremos desde el análisis arqueológico de la producción, reproducción y transformación social durante el nodo de la transición de cazadores-recolectores a sociedades agropastoriles, bajo una aproximación teórica basada en la perspectiva de la agencia (Finlayson 2010; Robb 2010) y las prácticas (Bourdieu 1997, 2007; Giddens 1995).

\section{Contexto Geográfico-Ambiental y Paleoambiental}

Antofagasta de la Sierra se encuentra en los desiertos de altura de la Puna Meridional argentina, sobre los $3.500 \mathrm{msm}$. Posee un clima árido y frío, con intensa radiación solar debida a la altitud, gran amplitud térmica diurna/nocturna y baja presión atmosférica. Las precipitaciones son marcadamente estacionales (130 mm/año), estivales, y la evapotranspiración media anual alcanza $550 \mathrm{~mm}$, lo que origina un balance hídrico negativo (Grana, Tchilinguirian, Olivera et al. 2016). El río Punilla es el curso colector más importante de la red endorreica que desagua en la Laguna de Antofagasta. Sus principales tributarios son los ríos Cacao-Curuto, Miriguaca y Las Pitas (Figura 1).

Los estudios paleoambientales dan cuenta entre los 7.200 y 3.500 cal. a.p. (6.300-3.400 a.p.) de condiciones áridas con una distribución de los recursos en forma de mosaico en escala intra e intercuencal. Entre los 3.500 y los 1.600 cal. a.p. (3.400-1.600 a.p.), las condiciones eran relativamente más húmedas, con mayor desarrollo y estabilidad de humedales en toda la microrregión que implicó una disminución relativa de la heterogeneidad espacial en la disponibilidad hídrica (Grana, Tchilinguirian, Olivera et al. 2016). El mejoramiento de las condiciones de humedad y una mayor estabilidad se generalizaron en el área hacia los 3.000 cal a.p. (Grana, Tchilinguirian, Olivera et al. 2016; Grana, Tchilinguirian, Hocsman et al. 2016). De este modo, las sociedades puneñas locales interactuaron con un entorno ambiental fluctuante; éste constituyó un elemento coyuntural o conformador de la coyuntura que nos ocupa, que será materia de discusión más adelante.

\section{Conceptualizando la Noción de Transición: Variabilidad, Cambio y Continuidad}

El estudio de las transiciones en la arqueología contemporánea es un tema de gran interés $y$, en particular, la transición a la producción de alimentos (Larson et al. 2014; Smith 2014; Starr 2005), aunque su tratamiento es relativamente reciente en Antofagasta de la Sierra.

Las investigaciones, desde la década de 1980, fijaron su interés en dos momentos de la secuencia arqueológica local. Uno de ellos correspondía a las ocupaciones iniciales del territorio y su uso posterior por parte de grupos de cazadoresrecolectores, los que, según el conocimiento actual, se basaron primordialmente en la caza de camélidos silvestres y se caracterizaron por redes de interacción de larga distancia y por un proceso paulatino de reducción de la movilidad residencial (Aschero 2010). El otro se centró en las ocupaciones de sociedades agropastoriles plenas caracterizadas por un sedentarismo dinámico que ponía en relación bases residenciales con sitios logísticos, entre los que se incluían puestos pastoriles a diferentes cotas altitudinales y que mantuvieron los componentes de caza y recolección; deviniendo luego, en las sociedades complejas del tardío local (Olivera 1988). Durante dos décadas la arqueología regional careció de un programa estructurado para el abordaje del tránsito a la producción de alimentos. En su lugar, existieron estudios de temas puntuales de contextos correspondientes a la cronología 


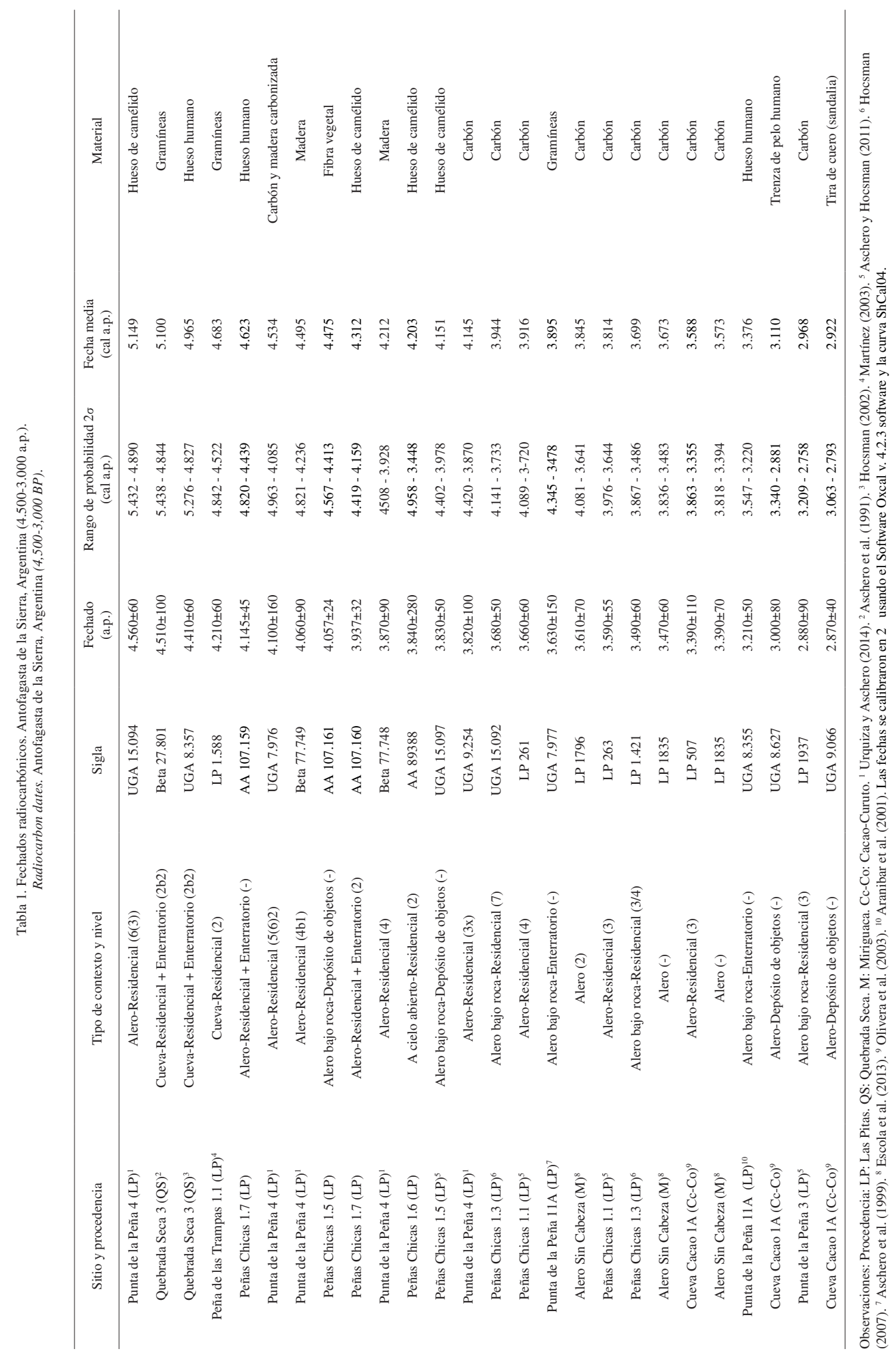




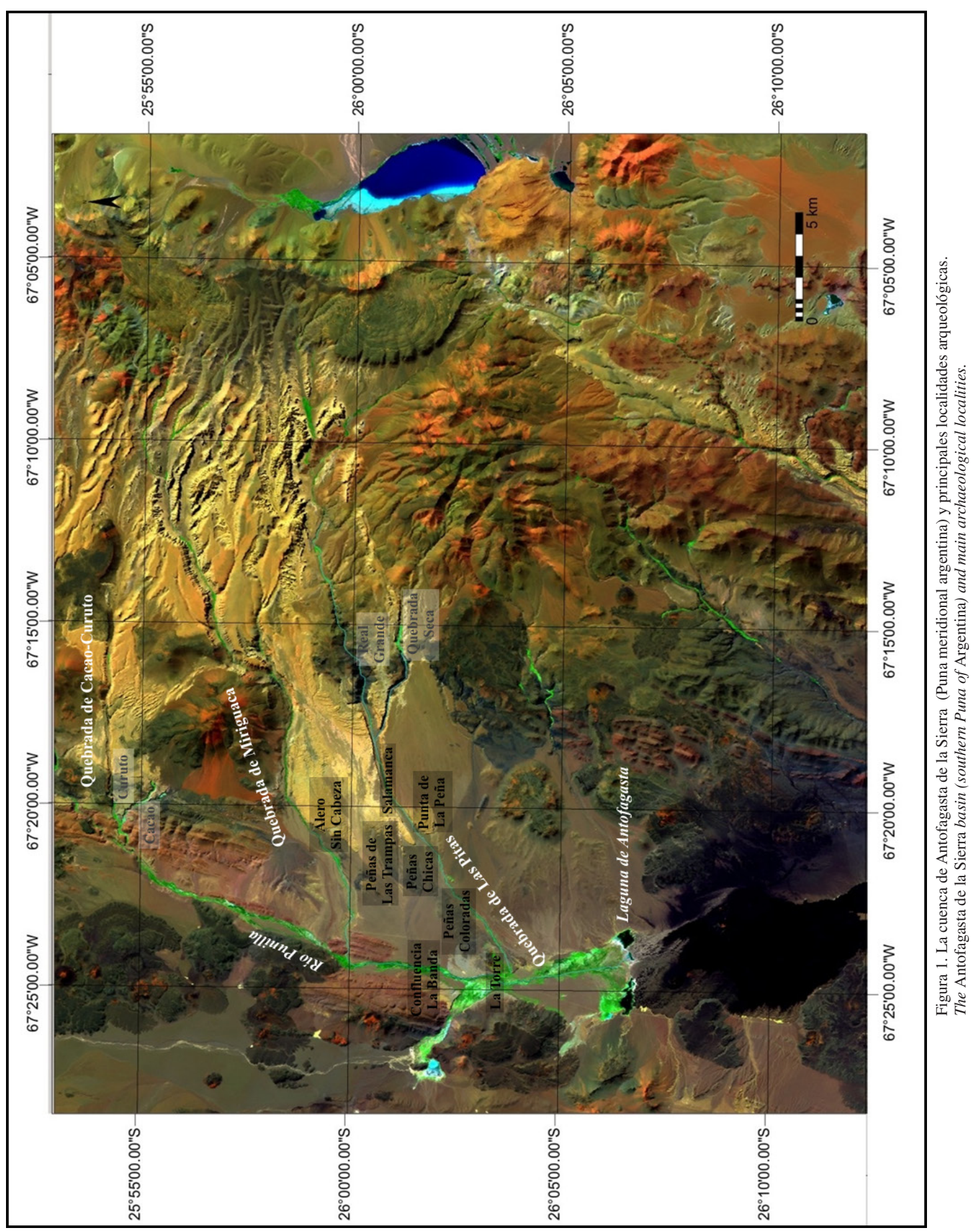


involucrada (Aschero et al. 1991; Pintar 1996); la incorporación local de camélidos domesticados, que se abordó desde la evidencia osteométrica y de cambio de fibra (Elkin 1996; Reigadas 2001; entre otros); las características de la tecnología lítica (Pintar 1996); incluyendo observaciones sobre la estructuración del espacio (Aschero et al. 1991; Aschero et al. 1993-94); las modificaciones en el acceso y uso de los recursos vegetales locales y foráneos (Rodríguez 2004; entre otros) y aspectos de los repertorios rupestres (Aschero 2006; entre otros).

Desde comienzos del 2000, la intención de nuestras investigaciones fue contribuir a dar entidad propia a ese momento intermedio de la ocupación local, dada la percepción de que el tránsito a la producción de alimentos constituía un tema y un problema relevante en sí mismo para el área de estudio. Para eso era necesario su abordaje desde una perspectiva integral, desde múltiples líneas de evidencia (Aschero y Hocsman 2011). El interés estaba puesto en considerar el proceso de cambio entre dos modos de vida ya definidos en el área, dándole un papel preponderante al momento de la secuencia ocupado por grupos que no se encuadraban plenamente en los conceptos de cazadoresrecolectores y sociedades agropastoriles, a los que les correspondía una coyuntura propia. Para eso era necesario considerar una parte de la trayectoria lo suficientemente larga que incluyera los cambios y las continuidades involucrados en la transición, así como los momentos previos y posteriores (Odell 1994), ya que se había trabajado con los puntos de inicio y final del proceso de cambio, pero faltaba establecer con precisión qué sucedía entre ambos (Smith 2001). Un concepto central en nuestro abordaje era que los cazadores-recolectores y los grupos agropastoriles son considerados como los extremos de un continuum, entre los cuales hay numerosas situaciones posibles (Ellen 1994; PanterBrick et al. 2001; Smith 2001). Por otro lado, en un análisis de largo plazo en una trayectoria local dada, la transición y/o el extremo productor pueden estar ausentes por lo que el uso que aquí damos al concepto carece de un carácter finalista.

Las denominaciones de "transición a la producción de alimentos" o bien, "tránsito de cazadoresrecolectores a sociedades productoras de alimentos" (en adelante TPA) -sociedades agropastoriles en nuestro caso de estudio-, son reduccionistas, ya que hacen primar un aspecto, el de la subsistencia, dado por el manejo animal o vegetal, por sobre otros no menos importantes (sociales, ideológicos, etc.). No obstante, para que la trayectoria transicional sea considerada tal debe, como punto de partida, referir a prácticas extractivas versus productivas en contextos de cambio o a una combinación entre ambas, sin detrimento del estudio integral de la nueva configuración de la sociedad implicada en la transición. Starr (2005) y Barnard (2007) se han referido a los modos de ver al mundo involucrado en las diferencias en la subsistencia, por lo que al aludir a un modo de vida cazador-recolector o productor, por ejemplo, ineludiblemente se apela a múltiples sentidos que indudablemente superan al solo mecanismo implicado en la adquisición de los alimentos. Los términos que empleamos nos limitan en todos los ámbitos de la disciplina, siendo fundamental el contenido y el uso que les damos. En el caso que nos ocupa, sociedades de la TPA se alinea con las nociones de cazador-recolector y de agricultor o agropastoril, no exentas de discusión (Ellen 1994; Kelly 1995), no obstante, superadoras de otras más normativas y generalizadoras como las del Arcaico y Formativo (Muscio 2001, 2009).

Las nociones de tránsito y de transición implican "la acción y efecto de pasar de un estado a otro distinto" (Diccionario de la RAE). Desglosado, el término implicaría acciones o situaciones, un lugar y un momento intermedio en que algo se transforma, de cierta duración, con tendencia a desaparecer, donde coexisten resabios del estado anterior y del nuevo, hasta que éste termina por definirse. Si bien el término "estado" puede evocar un paquete de rasgos y algo estático, y la idea de imposición final puede conllevar la perspectiva de una elección consciente hacia una meta deseada o conocida de antemano, no sostenemos estos postulados.

La transición es vista aquí como una situación intermedia entre otras, donde hay un momento inicial " $x$ " a partir del cual se desarrolla un momento transicional "y", que culmina en un momento "z", apreciable en la escala de largo plazo de la trayectoria de una sociedad, pero sin implicar que existió un movimiento "consciente" hacia un determinado objetivo en el pasado, sumado a un tiempo prolongado en el que operaron los cambios en distintos aspectos (Larson et al. 2014). Esta situación particular en una trayectoria local, implica configuraciones particulares de características que difieren de las de otras trayectorias, a diferencia de un estadio de desarrollo.

Considerar a la TPA como un proceso global posee sus atractivos y significancia (Gremillion et al. 2014; Larson et al. 2014), pero lo que aquí quisiéramos destacar en especial del concepto de transición es su referencia a las circunstancias específicas que caracterizan a la trayectoria concreta de las sociedades y que quedan relativamente definidas por lo previo y lo posterior. De este modo, a diferencia de un enfoque finalista y universal, las TPA deben primariamente definirse y verificarse en las trayectorias locales, con los ritmos, tiempos y particularidades que les corresponden sin pretender 
la uniformidad regional y, a la vez, sin negar las instancias de coparticipación en esa escala.

Se ha planteado que el proceso transicional es de larga duración y gradual (Smith 2001; Hodder 2017), o bien, rápido y radical. En este sentido, Marsh (2015, 2016) sostiene que la emergencia del agropastoralismo en la cuenca del Lago Titicaca se dio rápidamente, en 400 años radiocarbónicos, al considerar el inicio del proceso transicional local ca. 3.500 a.p. Pero, ¿debería ser retrotraído en el tiempo de acuerdo con los datos de Haas y Llave (2015), entre otros? Tales autores identifican en el sitio Soro Mik'aya Patjxa una ocupación de cazadores-recolectores tardíos que cuenta con fechados entre 8.000 y 6.700 cal. a.p. Presenta ciertos elementos que anticipan desarrollos posteriores de la cuenca del Titicaca, como evidencias de prácticas de subsistencia intensivas y violencia interpersonal que son el preludio de la emergencia del sedentarismo incipiente, la producción de alimentos y la territorialidad. Entonces, es crucial identificar cuándo se inició la domesticación o introducción de los camélidos, quenopodiáceas y tubérculos en el área, y si los actuales umbrales se deben a limitaciones metodológicas (de preservación y/o identificación osteométrica y arqueobotánica), o si existen sesgos debido a la falta de localización de los sitios relevantes (problemas de muestreo, visibilidad, conservación, etc.). Estos son problemas extensivos a todas las áreas de estudio.

Por otra parte, el cambio implicado en una transición no es privativo de los contextos TPA. Los cazadores-recolectores varían de toda forma posible y han sufrido transformaciones al igual que los grupos productores (Kelly 1995; Price y Brown 1985; RowleyConwy 2001).

Asimismo, los cambios no son necesariamente homogéneos, pueden variar en su escala y maneras de presentación. Por esto, la transición que nos ocupa no debe ser considerada un proceso unívoco, unidireccional e irreversible; el paso obligado e irrenunciable hacia la adopción de la agricultura, el pastoralismo u otras formas de producción por poblaciones basadas en recursos silvestres (RowlyConwy 2001). Puede haber, por ejemplo, soluciones económicas que combinan una dependencia de bajo nivel de especies domesticadas (Smith 2001) con un uso sostenido de recursos silvestres, en forma estable y en el largo plazo. Al respecto, Aschero y Hocsman (2011) plantearon que, en el caso de Antofagasta de la Sierra, la TPA involucró un "cambio con continuidad".

Un proceso TPA implica a cazadores-recolectores que incorporaron prácticas agrícolas en sentido amplio y/o ganaderas en su estrategia de vida y no su reemplazo por grupos productores (extinción/ migración). Estas situaciones pudieron ocurrir en el pasado, pero no se encuadran dentro del concepto de transición en los términos aquí planteados. Al respecto, pueden señalarse distintas posibilidades: (1) inicio de prácticas domesticadoras en el seno de los cazadores-recolectores; (2) incorporación de prácticas agrícolas y/o ganaderas por contacto con grupos productores; y (3) obtención de plantas comestibles domesticadas o de plantas cultivadas en general, por interacción con grupos productores (Aschero y Hocsman 2011). Un contexto TPA se verificaría en los dos primeros casos, donde la caza, recolección y/o pesca se mantienen.

Las situaciones TPA pueden aparentar relativa homogeneidad a escala microrregional. No obstante, en un contexto general de TPA ciertos individuos, familias o grupos podrían desarrollar prácticas domesticatorias o incorporar fauna domesticada y/o prácticas de cultivo, y paralelamente otros, mantener los modos de caza-recolección, o combinar diversas prácticas extractivas y productivas, y variaciones dentro de ellas. Los escenarios seguramente fueron extremadamente variables, al habitar los mismos lugares pero tomando diferentes elecciones sobre cómo desarrollar su vida. Por otro lado, las trayectorias locales en una macrorregión pueden mostrar una predominancia de ciertas opciones por sobre otras, sin que esto implique la ausencia de la variación interna anteriormente referida. Así, no todos los individuos, familias, grupos corresidentes y otras formas de organización en la micro y macro escala participarían necesariamente del proceso o bien, podrían hacerlo y revertirlo (Rowley-Conwy 2001), al contrario de lo sostenido por Robb (2013:657) sobre la dificultad de reversión local de la producción de alimentos: "(...) the Neolithic was easy to get into but hard to get out of".

Con respecto a estas elecciones, se plantea que los individuos actúan estratégicamente dentro de contextos históricamente específicos y de condiciones cuyos límites están definidos culturalmente (Dobres y Hoffman 1994). Esta es una aproximación alternativa a las posiciones del individuo "racional" y "optimizador", ya que considera el rol de las percepciones y experiencias vividas, así como factores ideológicos y simbólicos, además de los ambientales y biológicos.

\section{Una Aproximación a la Transición desde la Perspectiva de la Agencia}

El considerar a agentes históricamente situados practicando sus rutinas de la vida diaria es una forma apropiada de examinar un contexto de tránsito a la producción de alimentos como el abordado (Bruno 2009; Finlayson 2010). Es central el tratamiento de la cotidianeidad de las personas y de los grupos sociales, caracterizados por cualidades y circunstancias comunes, como ser maneras tradicionales de hacer y usar las cosas. Esta perspectiva es considerada aquí mediante el abordaje de prácticas sociales tanto en la cuenta larga como en un enfoque sincrónico, en 
su vinculación con configuraciones específicas de características de asentamiento, producción, circulación y consumo de alimentos, y confección de tecnofacturas, a escala microrregional.

Nos interesa el análisis de la producción, reproducción y transformación social en la TPA en Antofagasta de la Sierra. Para ello, se parte de una noción de agencia bajo la órbita de la "teoría de la práctica" (Bourdieu 1997, 2007) y de la "teoría de la estructuración" (Giddens 1995), que abordan las relaciones entre el "agente", un individuo acotado pero no determinado que puede alterar estructuras a través de la práctica, y la "estructura", los medios y condiciones más amplias y de mayor perduración que resultan de las relaciones entre los individuos. Si bien no hay unanimidad en la aplicación y en los significados del concepto de agencia (Dobres y Robb 2000a; Dornan 2002), se acepta que es la manera en la que las estructuras sociales "habitan en" y "empoderan a" los agentes; los objetivos, ideales y deseos de esos agentes y las condiciones materiales de la vida social, aunque teniendo presente que las acciones no intencionales de los agentes pueden ser tan importantes como las intencionales (Dobres y Robb 2000b).

La teoría de la estructuración se basa en la "dualidad de la estructura", que implica que las propiedades estructurales de los sistemas sociales son tanto un medio como un resultado de las prácticas que los agentes organizan de manera recursiva (Giddens 1995). Este concepto, sin negar los constreñimientos que existen sobre los agentes, coloca un fuerte acento en la acción y el poder del actor, de tal modo que éstos tienen capacidad de introducir transformaciones en el mundo social. Individuo y sociedad no son polos opuestos "mutuamente excluyentes" de la vida social, sino que se producen y reproducen de manera indisociable (Finlayson 2010).

Para Giddens (1995), el agente se constituye como un ser reflexivo, monitoreando reflexivamente el conjunto de sus acciones. La mayor parte de sus acciones cotidianas no es directamente motivada ni puede ser tampoco directamente elaborada en la forma de discurso. Sin embargo, esa motivación indirecta y la incapacidad discursiva de los agentes con relación a la mayoría de sus acciones (conciencia práctica), no es impedimento para "llevar una vida normal", interactuar mutuamente y ejecutar sus actividades cotidianas. Esta característica de la vida cotidiana lleva hacia uno de sus elementos fundamentales: la "rutina" o, en términos de la teoría de la estructuración, la "rutinización". La repetición cotidiana de prácticas sociales idénticas o similares es lo que posibilita la reflexividad del agente. Esto es clave, porque si las prácticas sociales fuesen efímeras (y/o únicas) no sería posible el conocimiento por parte del sujeto del ambiente de actuación ni, por tanto, la acción innovadora, creativa.
Las prácticas cotidianas de los individuos (campo de acción de los agentes) son delimitadas por las propiedades estructurales que presentan los sistemas sociales en condiciones espacio-temporales determinadas. Estas propiedades son permanentemente renovadas. Por eso es de particular interés abordar sus configuraciones cambiantes en tiempo y espacio y las situaciones de "coyuntura" (sensu Marks 2007) en las trayectorias locales (Aschero 2016).

Bourdieu $(1997,2007)$ incorpora la dimensión analítica consciente de los actores sociales y, a la vez, su dimensión histórica a partir del concepto de habitus, que proporciona elementos para abordar la producción, reproducción y transformación social. El habitus involucra sistemas de "disposiciones" duraderas y transferibles, estructuras estructuradas predispuestas para funcionar como estructuras estructurantes, es decir, como principios generadores y organizadores de prácticas y representaciones que pueden estar objetivamente adaptadas a su fin sin suponer la búsqueda consciente de fines y el dominio expreso de las operaciones necesarias para alcanzarlos (Bourdieu 2007). Así, el individuo no reacciona mecánicamente ante las situaciones que se le presentan, sino a través de su habitus socialmente interiorizado. Sin embargo, a través de sus prácticas, el agente tiene la posibilidad de actualizarlo en función de un contexto que le permite producir prácticas transformadoras. Esto ocurre cuando los habitus quedan desfasados frente a nuevas realidades. De este modo, tienen la posibilidad de cambiar continuamente en función y a partir de experiencias nuevas, es decir, de las prácticas mismas (Bourdieu 1999). En casos como la TPA es factible abordar los cambios en las prácticas y habitus en la cuenta larga (Bruno 2009).

Una de las dimensiones en las cuales se halla implicada la agencia, tanto de personas como de cosas, es en la creación, negociación y transformación de la identidad de las personas y de las identidades colectivas (por ejemplo, Finlayson 2010). De hecho, las similitudes y diferencias en las prácticas (del comer, del vestir, etc.) contribuyen de manera dinámica a la definición de las identidades (Gardner 2011).

\section{Perspectivas de la Transición a la Producción de Alimentos en Antofagasta de la Sierra}

Las evidencias de un proceso local de cambio socioeconómico de grupos cazadores-recolectores a sociedades agropastoriles en Antofagasta de la Sierra entre los 4.500 y los 3.000 a.p. son significativas y variadas (Figura 2, Tabla 1). Comprenden, entre otros aspectos: disminución de la movilidad residencial; emergencia de territorialidad; interacción a grandes distancias que posibilitó el intercambio de elementos 
bióticos y abióticos, tecnofacturas e información sobre prácticas diversas; mayor densidad poblacional; intensificación en el manejo de animales y plantas, implicando situaciones de domesticación/apropiación de técnicas productivas; cambios e incorporaciones tecnológicas tales como la cerámica; e intensificación en el procesamiento vegetal (Aschero y Hocsman 2011; Babot 2014; Babot y Hocsman 2015; Hocsman 2014; Rodríguez 2013; Urquiza y Aschero 2015; y trabajos allí citados a cuya consulta remitimos por motivos de espacio). A continuación consideramos algunos aspectos destacados.

\section{Estudio de las plantas, las comidas y las prácticas culinarias}

En esta sección nos referimos a los aportes del estudio de las plantas, las comidas y las técnicas culinarias sobre las circunstancias de la TPA en Antofagasta de la Sierra. Tomamos las tendencias de estos aspectos en la trayectoria local como una relación íntima entre los integrantes de las sociedades locales y las plantas, resultante de necesidades, pero también de elecciones, del interés y el impacto mutuo de larga data (Hastorf 2006), al considerarlos como agentes activos en la incorporación de nuevas prácticas en la TPA.

Los estudios tecnológicos y de uso del instrumental involucrado en la vida cotidiana de las sociedades puneñas (residuos en artefactos cerámicos, líticos tallados y de molienda, más inclusiones en el tártaro dental) permitieron aproximarnos a los modos de uso de las plantas, especial pero no exclusivamente, los referidos a la alimentación y a las prácticas ordinarias que los incluyeron (Babot 2016 y trabajos citados allí). Estos estudios, desarrollados en la cuenta larga pusieron en evidencia los cambios operados durante la TPA que discutimos más adelante sobre la base de los datos resumidos en la Tabla 2. En particular, el análisis realizado en el instrumental de molienda de este lapso proporcionó indicadores de una práctica regular y establecida en las unidades domésticas transicionales, denotada por una mayor ubicuidad y diversidad artefactual. También se verificó un incremento en la eficiencia e intensidad de uso de las piedras de moler según numerosos indicadores registrados de tipo tecnológico -referidos a la inversión en la manufactura de las piezas y a la selección de mejores materias primas líticas- y de uso -particularmente observables en un mayor grado de desgaste y en su administración mediante mantenimiento- (Babot 2014 y trabajos allí citados).

Según lo apreciable a lo largo de la secuencia ocupacional local, la molienda formó parte de múltiples procesos de elaboración de alimentos y de elementos no alimenticios. Entre estos últimos se encontraban el trabajo artesanal de la corteza de Lagenaria siceraria (mate) y la semilla de Canna edulis (achira), procedentes de las Yungas (aproximadamente $170 \mathrm{~km}$ desde los sitios); la hoja y pecíolo de Acrocomia sp. (chonta) de las Yungas en el extremo norte del Noroeste Argentino (aproximadamente $400 \mathrm{~km}$ desde los sitios); y poáceas silvestres locales (Babot 2014, 2016). Con respecto a los alimentos, las técnicas involucradas en la manipulación de molinos y morteros (el continuo molienda / trituración / machacado / partido / pelado) serían esenciales en la habilitación para el consumo de un conjunto de frutos, semillas, legumbres, tubérculos, rizomas y tallos frescos -taxones señalados con asterisco (*) en la Tabla 2- (Babot et al. 2012; Lund 2016), implicando esto, tanto su habilitación física, como fisiológica y del gusto.

Ciertos procedimientos y preparaciones culinarias, que implican modos de consumo tradicionales andinos y determinados requerimientos de elaboración de los alimentos para su ingesta, documentados en el folclore, la etnografía y la etnohistoria regional, podrían ser muy antiguos en la región (Babot 2014; Babot et al. 2012; Lund 2016) (Tabla 2). Considerando el total de información arqueobotánica disponible para el área de estudio sobre plantas útiles en la alimentación (Babot 2014; Pintar y Rodríguez 2013), es posible sostener que entre las técnicas de muy larga data se encontrarían el asado al fuego directo o al rescoldo (entre cenizas y brasas) de tubérculos y raíces silvestres no determinados y correspondientes a ciperáceas y a los géneros Hoffmanseggia y Juncus; su pelado y descascarillado; el asoleado y la elaboración mediante la molienda / machacado / triturado de pastas dulces o saladas (Babot et al. 2012). También tendría lugar la ingesta directa como en el caso de las raíces de Festuca. El uso de tales plantas, de colecta local y próxima a los sitios, en comunidades de vega y tolar (menos de $1 \mathrm{~km}$ ), indicaría su consumo en fresco (Babot 2014). En cambio, los granos del género Amaranthus, las tunas de Opuntia y, eventualmente, el maní, habrían requerido el machacado por proceder potencialmente secos de los valles templados o mesotermales (aproximadamente $100 \mathrm{~km}$ desde los sitios en línea recta) en los dos primeros casos, y de las Yungas (aproximadamente $170 \mathrm{~km}$ desde los sitios en línea recta), en el último de ellos.

En particular, durante la TPA e inmediatamente previo a ella, los procedimientos culinarios se intensificaron y diversificaron (Tabla 2). El tostado de granos, especialmente, quinua y, en alguna medida, coimi, maíz y gramíneas silvestres tomarían un lugar importante en la alimentación cotidiana junto a otros procesos asociados como el descascarillado, el aventado y el desgranado. También lo harían la molienda / machacado de éstos y de frutos como la algarroba, tuna y nuez criolla para obtener pastas y harinas potencialmente empleadas en amasados 


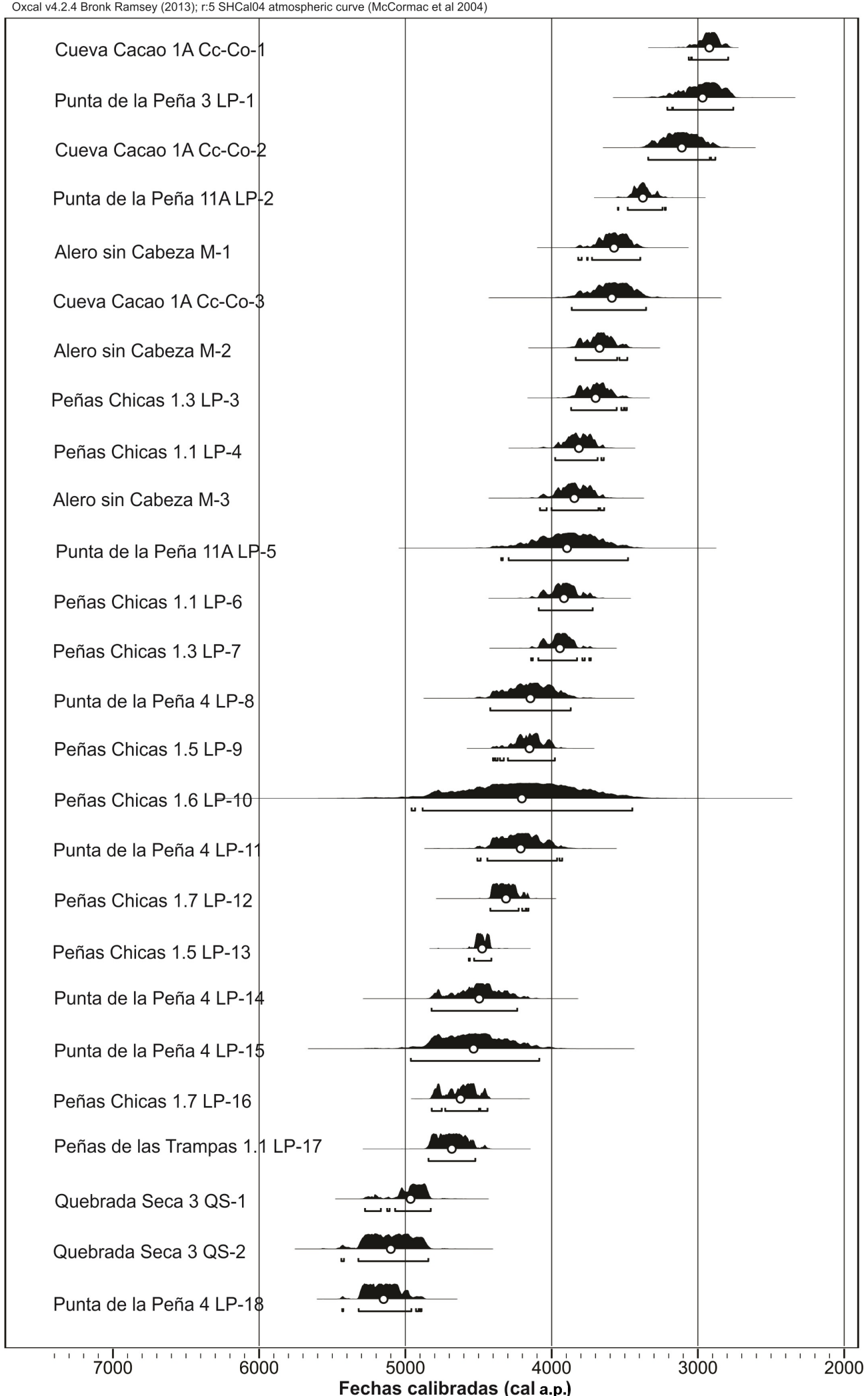

Figura 2. Dataciones radiocarbónicas calibradas de la cuenca de Antofagasta de la Sierra (Puna meridional argentina) para el lapso 5.500-3.000 años cal. a.p. Calibrated radiocarbon dates of the Antofagasta de la Sierra basin (southern Puna of Argentina) between 5,500-3,000 years cal BP. 


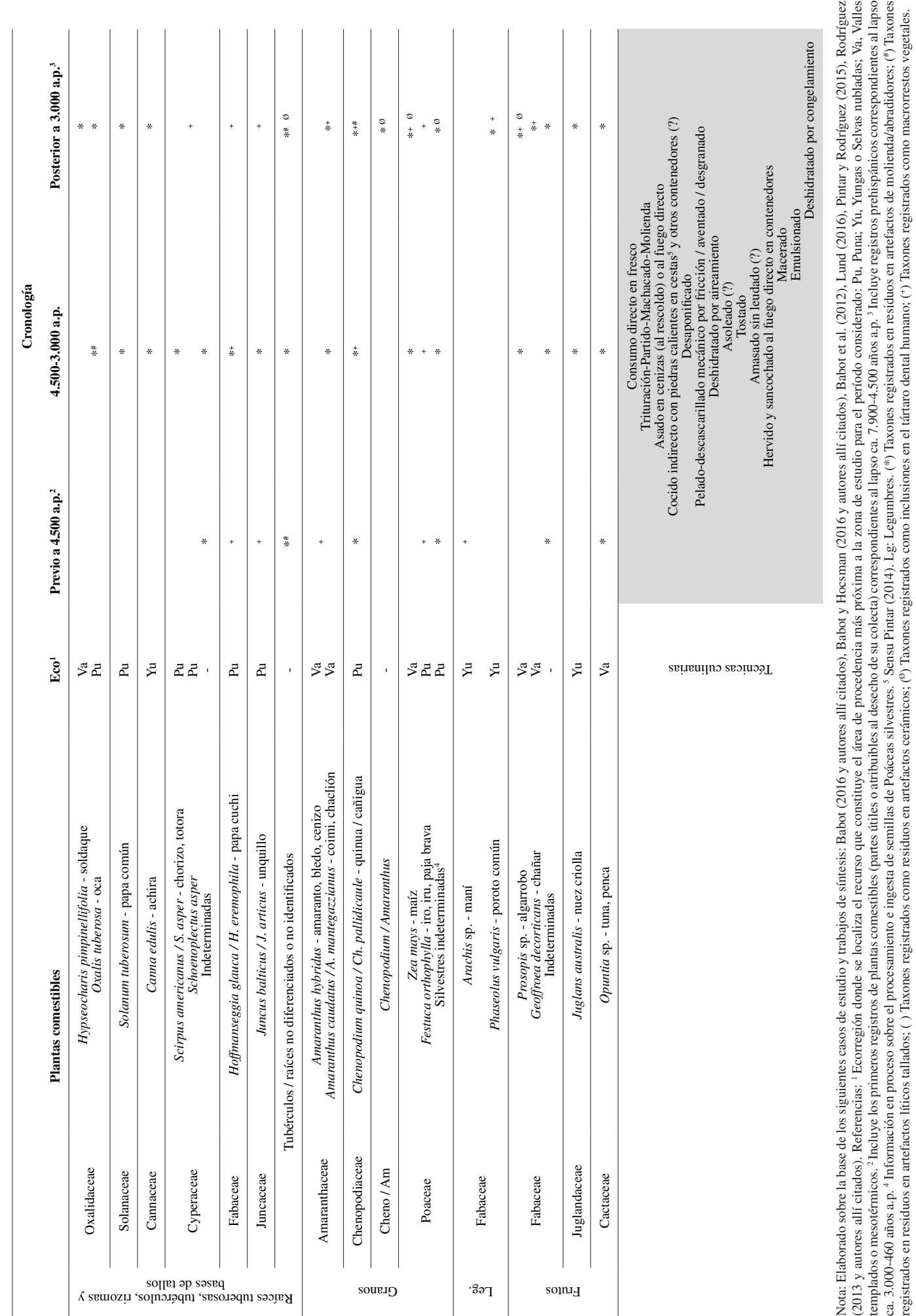


sin fermentos y en bebidas refrescantes. A ello se sumaría el machacado de partes útiles de plantas con órganos de almacenamiento subterráneo -en adelante POAS- (sensu Ochoa y Ladio 2011), tanto domesticadas (papa común, oca y achira) como silvestres. De igual modo, se introduciría el hervido / sancochado, desde la incorporación de la cerámica y otras técnicas específicas como el desaponificado requerido por la quinua.

El consumo de elaboraciones basadas en elementos secos, en especial harinosos, resultantes de prácticas de desecado o deshidratado por aireamiento, debido al almacenamiento, se regularizaría (Babot 2014; Babot et al. 2012). Estas preparaciones formarían parte de las comidas cotidianas y, por lo tanto, de las preferencias culinarias de la TPA, concomitantes con una mayor incorporación de alimentos de origen no puneño, procedentes de los valles templados (coimi, maíz, tuna y algarroba, pudiendo esta última proceder también del norte chileno) y las Yungas (nuez criolla, achira); el inicio del uso de plantas domesticadas y la producción de alimentos mediante su cultivo o fomento local (quinua, oca, papa común y papa cuchi) que favorecerían, en su conjunto, el manejo y la circulación de un volumen mayor de alimento vegetal.

Estos indicadores del consumo diario se refieren a la internalización cotidiana de los alimentos socialmente aceptables en la TPA, abarcando las pautas y circunstancias de preparación y consumo de la comida (cuándo, cómo, cuanto y por quién), además del campo extendido de las prácticas de producción, colecta, post-colecta y circulación de los elementos comestibles (Atalay y Hastorf 2006; Smith 2006). Como ha sostenido Hodder (2017), estos vínculos dan cuenta de la complejidad de las interrelaciones entre los artefactos, las plantas, las secuencias operativas y todos los otros elementos involucrados en estas prácticas.

Esto resultaría en una "naturalización del gusto" (sensu Ayora Díaz 2014); distintas sensaciones se encontrarían ligadas a la ingesta, inclusive el "metasentido de la memoria" y la "afectividad" (Hamilakis 2015; Hastorf 2006). De este modo, los alimentos serían un componente de la cohesión social (Smith 2006) y, por lo tanto, un elemento fuertemente identitario. Su valor social tan internalizado sostendría los esfuerzos implicados en los viajes para la obtención de los elementos foráneos, y todo el trabajo de procesamiento posterior para su consumo, superior a la ingesta en fresco.

Las nuevas técnicas culinarias habilitarían el consumo de los elementos llegados en estado deshidratado y de los que se mantendrían así en el tiempo, debido a la distancia temporal entre su colecta y su adquisición, traslado, elaboración y consumo (Babot 2014). Así, la opción por tales técnicas y los alimentos procesados posibilitaría los intercambios de bultos, que no serían exitosos sin todo el conocimiento práctico requerido para la elaboración de alimentos secos. Las potencialidades del almacenaje en situaciones de movilidad residencial reducida han sido largamente estudiadas (Cunningham 2011) y nuestro caso de estudio lo refleja. Nos referimos básicamente a un volumen de alimento seco procedente de colectas y multiplicado en los cultivos próximos y lejanos, factible de ser racionado en el tiempo y elaborado en nuevas formas.

En la TPA las sociedades del desierto habrían puesto en marcha un espectro de prácticas de manejo de plantas alimenticias: cultivo de baja escala en huertas de tubérculos y granos comestibles domesticados -quinua, oca, papa-; obtención de granos, rizomas y frutos de plantas domesticadas cultivadas y de frutos de plantas silvestres foráneas; colecta de rizomas, tubérculos y tallos frescos en la flora nativa silvestre (Babot 2016; Babot y Hocsman 2016; Lund 2016), que podrían haber estado bajo fomento en los humedales de altura o bajo cultivo en las huertas (Lund 2016). Todas estas modalidades informan acerca de la intención de intervenir, colaborar e involucrarse en los ciclos naturales vegetales con el fin de la producción de alimentos mediante una gama de estrategias agrícolas en sentido amplio, implementadas en el desierto junto con el pastoreo de camélidos y la caza (Olivera 1998, Olivera y Elkin 1994). Algunas de éstas, tales como la silvicultura de Prosopis, han sido propuestas, también, para el caso del Salar de Atacama en Chile (Mc Rostie 2014), como complemento del pastoreo.

Las interacciones sociales fundadas en relaciones de parentesco o alianzas, propuestas por Aschero (2016), posibilitarían el flujo regular de alimentos, hacia y desde la Puna. La inserción de tales consumos en la cotidianeidad y en momentos extraordinarios del ciclo anual actualizaría las redes y las relaciones sociales implicadas en ellas. Así, se habilitarían la partida y retorno de los viajes, anticipando y asegurando que los intercambios se concretarían. En este sentido, apelamos a Hastorf (2006) quien ha propuesto que la "adopción" de plantas foráneas, su movimiento y domesticación reflejan las elecciones realizadas por los individuos a través del tiempo que definen patrones tempoespaciales, así como una historia de socialización.

De este modo, sabemos que esos elementos se encontraban incorporados al uso ordinario. Ahora bien, ¿se trató de quiebres en las pautas de consumo? Si ampliamos la escala hacia los 
tiempos previos y posteriores a la TPA y salvando las diferentes intensidades de estudio de la alimentación previo a este momento, notamos un cambio con continuidad. Los estudios anteriores y recientes (Babot 2016; Rodríguez 2013 y autores allí citados) (Tabla 2) permiten sostener tres tradiciones de consumo muy tempranas en el área y de gran permanencia temporal referidas a semillas o granos, tubérculos y raíces y frutos.

Se ha sostenido que la dependencia en productos agrícolas implicada y resultante de las transiciones hacia la producción tuvo su antecedente en la colecta silvestre (Korstanje 2017; Larson et al. 2014; Olivera 1988; Snir et al. 2015). Si bien el planteo actual de la TPA puneña meridional no incluye una dependencia en la agricultura, la coparticipación en el proceso de domesticación (Larson et al. 2014) de granos andinos y tuberosas y la incorporación de su cultivo, tendrían sus precedentes en el conocimiento y uso previo de las POAS y semillas silvestres locales y foráneas por parte de los cazadores-recolectores del Holoceno Medio Final y Tardío Inicial. Por lo tanto, no implicarían un quiebre con los repertorios locales. La transición habría traído nuevos productos a la mesa, pero de cierta manera, formarían parte de pautas culinarias conocidas. Sin embargo, los nuevos elementos implicarían algunos cambios en el gusto: variantes en los sabores, texturas y preparaciones ${ }^{1}$.

Alimentarse nodebeserconcebidocomounamera necesidad fisiológica. Las preferencias culinarias operan a la escala de la sociedad, sobre la base de percepciones de sabor, valor, pureza, digestibilidad, facilidad o dificultad de preparación de la comida, disponibilidad de técnicas e instrumentos requeridos para ello y según lo que está permitido o vedado (Hamilakis 2015; Smith 2006); pero también lo hacen en la escala de las unidades domésticas y de los individuos, ya que lo que realmente se ingiere es el resultado de decisiones individuales realizadas en el marco de un contexto social dado. Esto es lo que permite definir a la ingesta como un acto esencial de identidad, conformidad o resistencia puesto en práctica diariamente (Smith 2006).

A partir de esto podrían plantearse a las pautas y preferencias culinarias como un componente de identidad social compartida que alcanzaría a toda la red implicada en la producción, colecta, circulación, elaboración y consumo de los alimentos documentados, con sus puntos en distintas ecozonas del norte argentino-chileno (Aschero y Hocsman 2011; Babot 2014).

En la escala de los Andes Centro-Sur, Antofagasta de la Sierra coparticipó junto a las tierras altas del sur boliviano-peruano y el norte chileno en los procesos domesticatorios y de cultivo tempranos de la quinua (Babot y Hocsman 2016; Bruno y Whitehead 2003; Winkel et al. 2017), la papa y la oca (Babot 2014;
Rumold y Aldenderfer 2016) así como del conjunto de prácticas sociales, preferencias y conocimiento práctico implicado en ello. El papel del maíz anterior a los 2.000 a.p. es aún una incógnita (Babot 2016; Núñez et al. 2009; Perry et al. 2006).

\section{Los lugares habitados y las residencias}

Numerosos análisis del uso de la flora, fuentes de materiales líticos, elementos minerales y la localización de lugares ocupados con distintos fines en la cuenca antofagasteña indican una relación íntima y de larga data de las sociedades locales con el espacio recorrido y habitado, desde el desierto extremo al humedal altoandino, y permiten establecer variaciones en los modos de habitar en distintos momentos de la secuencia local. Uno de ellos coincide con la TPA, a la que corresponde un número muy importante de sitios (Aschero y Hocsman 2011 y este trabajo) (Tabla 1, Figura 2). De particular relevancia son tres localidades arqueológicas muy próximas: Punta de la Peña, Peñas Chicas y Peñas de las Trampas (Figuras 1 y 3).

Esta porción de la cuenca comprende una serie de sitios residenciales en aleros rocosos dispuestos en farallones de ignimbritas y bajo bloques desprendidos, con espacios a cielo abierto adosados en Peñas Chicas (PCh1.1, PCh1.3., PCh1.7); sitios residenciales a cielo abierto en las terrazas aluviales próximas al río Las Pitas en Peñas Chicas (PCh1.6) y Punta de la Peña (PP12, PP1) y áreas de usos múltiples a cielo abierto en la Pampa inmediata a Las Pitas -Sectores 1 y 2 de Punta de la Peña Zona de Aprovisionamiento y Cantera -PPZAC- (Bobillo y Hocsman 2015)-. A estos se suman los enterratorios en Punta de la Peña (PP11) y depósitos intencionales de objetos en Peñas Chicas (PCh1.5). De estos, los sitios a cielo abierto con conservación orgánica insuficiente se han adscripto a la TPA en función de contener instrumentos líticos (puntas de proyectil, cortantes de filo retocado perimetral, entre otros) tecno-tipológicamente exclusivos de la TPA en la secuencia local y similares a los que proceden de la estratigrafía de los sitios en reparo asociados. PCh1.6 es el primero de ellos en arrojar una datación radiocarbónica (3.840 \pm 280 años a.p. sobre hueso).

En conjunto, definen un nuevo modo de habitar mediante la estructuración de un área acotada dentro de una misma quebrada con una notable densidad y diversidad de espacios, resultando en un esquema de lugares de residencia y sitios asociados dispersos pero próximos (Aschero y Hocsman 2011). La habitación de espacios abiertos como lugares de residencia y como áreas de usos múltiples no tiene correlato previo en el área y delimita una búsqueda deliberada de habitar y permanecer "hacia afuera" de los aleros. Los reparos rocosos Cueva Salamanca 1 (CS1), Punta de la Peña 4 (PP4) y Peñas de Las Trampas (PT1.1) difieren en la carencia de terrenos abiertos aledaños 


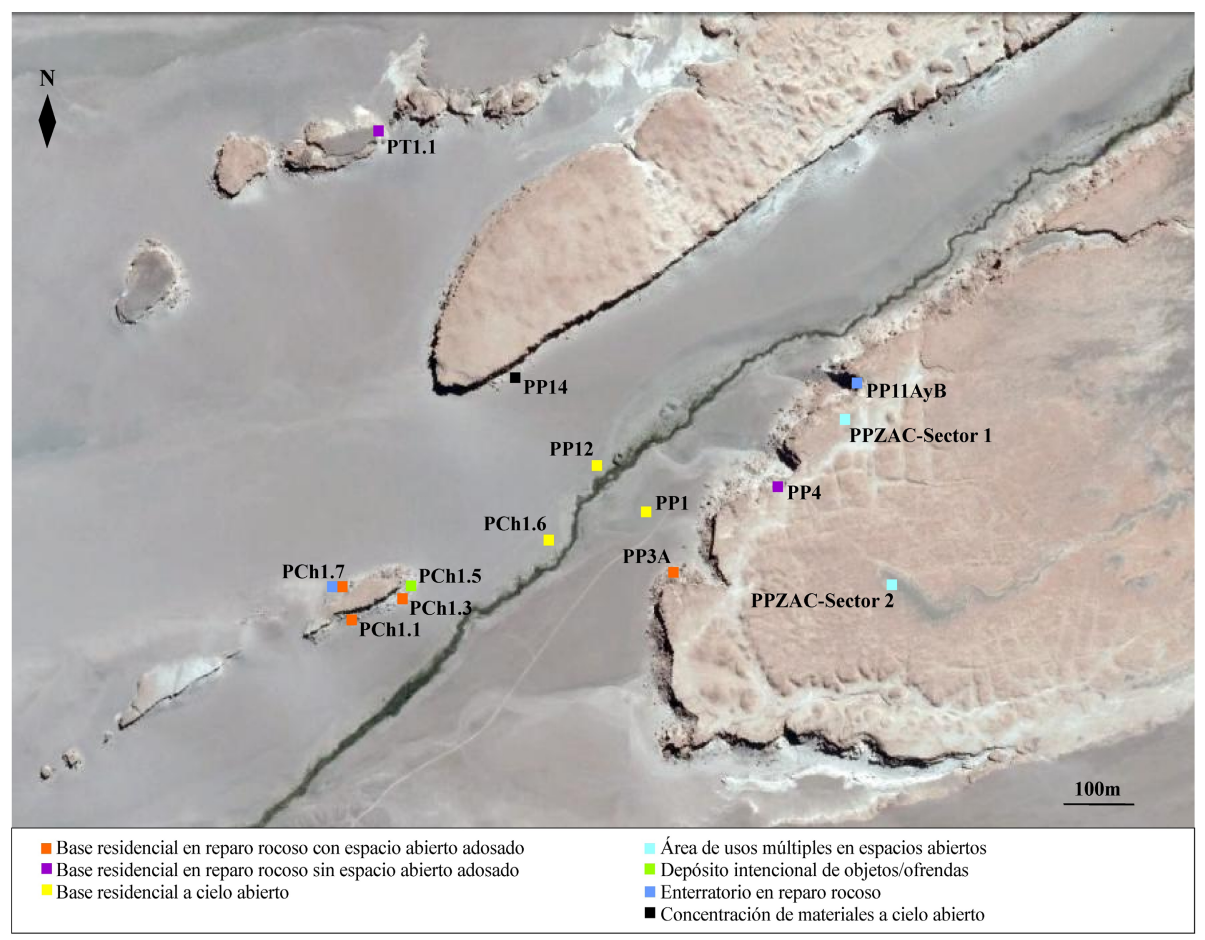

Figura 3. Sitios arqueológicos de Punta de la Peña, Peñas Chicas y Peñas de las Trampas para el lapso 4.500-3.000 años a.p. Archaeological sites from Punta de la Peña, Peñas Chicas and Peñas de las Trampas between 4,500-3,000 years BP.

debido a su posición topográfica, aunque algunas de las áreas de usos múltiples en PPZAC, próximas a PP4, podrían asociarse a este sitio. Corresponden a reparos ubicados en sectores superiores y elevados de los farallones. Estos lugares persistentes, de uso muy antiguo, habrían permanecido activos en la memoria y en las prácticas de las sociedades locales, a la vez que se habilitarían por primera vez otros, cercanos o sobre las planicies adyacentes a los cauces en un movimiento "hacia abajo". La cotidianeidad de las nuevas prácticas productivas se volcaría hacia los humedales promoviendo su cercanía, mientras que nuevas pautas de residencia resolverían la proximidad de las viviendas en sectores favorecidos de la cuenca. El uso recurrente de los espacios abiertos marca un punto de inflexión en las formas locales de habitar y es el prolegómeno de lo acaecido a posteriori en las sociedades agropastoriles. Apelamos a la noción de aménagement (Delannoy et al. 2013), que implica una configuración social activa de los lugares para indicar que había una nueva forma de concebir los espacios y las residencias que significó una construcción social novedosa del habitar.

Aunque aún no es el caso de los sectores a cielo abierto, en el interior de los reparos rocosos o en su línea de goteo se dispusieron estructuras de piedra habitacionales (sitios PP4, PCh1.3 y PCh1.7). Esta práctica innovadora de la construcción en piedra puede ser vista como un reflejo de la constitución de lo social e implicaría cambios en la percepción y en las formas de entender los lugares y los espacios por las personas (Boyd 2006; Craig 2012).

\section{Señalización de identidad a escala microrregional}

Aschero (2006, 2007) planteó una situación de variantes en las representaciones de camélidos en el arte rupestre de Antofagasta de la Sierra, implicando diferentes "estilos" dentro de la modalidad estilística Río Punilla, entre los 3.500 y los 2.500 a.p., distribuidos en distintas quebradas (Cacao/Curuto, Miriguaca y Las Pitas) y el fondo de cuenca (La Torre). Esto respondería a un contexto de circunscripción espacial y de competencia por los recursos en un área reducida -la distancia entre los tributarios del río Punilla es menor a 20 km- (Figura 1). En este marco, la localidad Confluencia-La Banda tendría un papel importante por reunir toda la variación estilística. Allí se habrían mediado los conflictos sociales con la puesta en práctica de rituales que favorecían la cohesión social y disminuían las tensiones (Aschero 2007). El ritual implica poderosas fuerzas sociales, colabora en la reproducción de la identidad colectiva y tiene una función de regulación social (Finlayson 2010).

La situación sugerida de virtual competencia por los recursos dado un contexto de aridez ha sido ratificada por los datos paleoambientales aportados por Grana, Tchilinguirian, Olivera et al. (2016) 
y Grana Tchilinguirian, Hocsman et al. (2016), sobre pulsos de mayor humedad relativa que se manifestaron con diferente intensidad y cronología en distintos sectores de la microrregión, aunque mayormente luego de los 4.800 cal. a.p. (ca. 4.400 a.p.). Éstos promovieron una alta heterogeneidad en la disponibilidad de recursos y variantes en la estabilidad ambiental de las diferentes quebradas y sectores dentro de las mismas. Particularmente, la alta heterogeneidad en la disponibilidad de humedales hacia los 3.8003.000 cal. a.p. (3.600-3.000 a.p.) generaría sectores específicos con mayor productividad de recursos bióticos y agua (Grana, Tchilinguirian, Olivera et al. 2016) y esenciales para las nueva prácticas productoras. Estos sectores favorecidos, limitados en número, habrían estado sujetos a competencia. Con posterioridad a los 3.000 a.p. se generalizaron las condiciones favorables en toda la cuenca (Grana, Tchilinguirian, Olivera et al. 2016), por lo que esta situación pudo haber cambiado, lo cual requiere ser estudiado a futuro.

Las divergencias en los diseños de puntas de proyectil en uso en las distintas quebradas entre los 3.800 y 3.000 a.p. estarían acompañando las diferencias en el arte rupestre. Son consistentes las divergencias entre los diseños de la quebrada de Las Pitas, por un lado, y los de Miriguaca y Cacao/ Curuto, por el otro (Figura 1). Mientras que Las Pitas presenta una multiplicidad de diseños pedunculados y apedunculados característicos, específicamente 13 diseños identificados como tipos morfológicos y cinco como especímenes morfológicos (Hocsman 2006, 2010, 2014), a Miriguaca -Alero Sin Cabeza (Escola et al. 2013)- y a Cacao/Curuto -sitio Cacao 4- les corresponden sólo dos diseños pedunculados, diferentes estilísticamente a los de Las Pitas (Figura 4). Cacao 4 carece de cronología absoluta pero presenta un conjunto artefactual tecno-tipológicamente asimilable a los de otros sitios del área posteriores a los 4.000 años a.p. (Peñas Chicas 1.1, 1.3 y 1.6 y Alero Sin Cabeza).

La diferenciación también operó en la materia prima elegida para la confección de las puntas de proyectil. Mientras que en Punta de la Peña se usaron primordialmente vulcanitas locales $(89 \%)$ -involucrando distancias menores a $15 \mathrm{~km}$ (Hocsman 2006, 2014)- y, secundariamente (21\%), obsidianas no locales -localizadas a distancias mayores a $40 \mathrm{~km}$ (Escola et al. 2016)-, en Miriguaca y Cacao predominan las obsidianas no locales (95\%). Los desechos de talla recuperados en Alero Sin Cabeza se alinean en el mismo sentido, ya que se observó una frecuencia muy alta de las variedades de obsidiana en dichos materiales por sobre las rocas locales (Spadoni 2015), contrastando con lo que sucede en los sitios contemporáneos de la quebrada de Las Pitas (Escola et al. 2016; Hocsman 2006, 2014).

Así, dentrodeunrepertorio tecnológicoy tipológico mayor claramente compartido (Hocsman 2006, 2014), las puntas de proyectil fueron concebidas y utilizadas por estos grupos antofagasteños como "diacríticos de identidad", es decir, como objetos empleados para la expresión de una identidad, posibilitando la diferenciación o el señalamiento de límites (Berón 2006), territoriales y/o sociales, en consistencia con las particiones ambientales contemporáneas.

Desde la perspectiva de la agencia, las acciones de los actores sociales individuales están inmersas en un entorno sociocultural y ecológico más amplio (Finlayson 2010), por lo que es posible sostener una situación de "coyuntura" (Marks 2007) que involucró diversas prácticas de señalización de identidades. Las situaciones ambientales variables y fluctuantes que acentuarían las características del ambiente extremo generarían desafíos y oportunidades para las poblaciones locales. Sus elecciones se manifiestan en la reformulación de los mecanismos de sociabilidad con nuevas negociaciones y regulaciones sobre el acceso a los lugares habitados de larga data y sus recursos, en la pertenencia a grupos de corresidencia y en la instauración de eventos colectivos que impactarían en la organización y desarrollo del ciclo anual del grupo mayor.

\section{Consideraciones Finales}

En situaciones como la que tratamos aquí, donde el tránsito hacia la producción de alimentos y el modo de vida agropastoril se produjo en el seno de cazadoresrecolectores locales, el concepto de transición es un término operativo que permite abordar y comprender qué es lo que sucede "entre" las zonas borde; en este caso, por un lado, los cazadores-recolectores y, por el otro lado, los grupos agropastoriles. Ese ámbito o lugar intermedio debe ser explorado en su variabilidad, cambio y continuidad. La información presentada y discutida aquí y en anteriores oportunidades afirma la idea de "cambio con continuidad" en lo local y da cuenta de un fenómeno altamente variable al interior de los Andes Centro-Sur (Aschero y Hocsman 2011; Craig 2011, 2012; Capriles et al. 2011; Dudognon y Sepúlveda 2016; López y Restifo 2014; Marsh 2015; Muscio 2001; Núñez et al. 2006; Núñez et al. 2009; Núñez et al. 2017; Salazar et al. 2015; Sepúlveda et al. 2017; Yacobaccio et al. 1997/98).

Existe consenso en que la producción, aprovisionamiento, procesamiento, cocción y consumo de la comida están altamente estructurados y constituyen un aspecto central de la vida diaria (Atalay y Hastorf 2006; Bruno 2009). En esa línea, se ha sugerido que un cambio en la manera de comer se encuentra en el corazón del tránsito a la producción de alimentos (Finalyson (2010). De particular importancia en este análisis son las tradiciones culinarias, que implican la historia culinaria compartida y anclada en un pasado común, sin ser concebidas como un legado inmutable, pues 


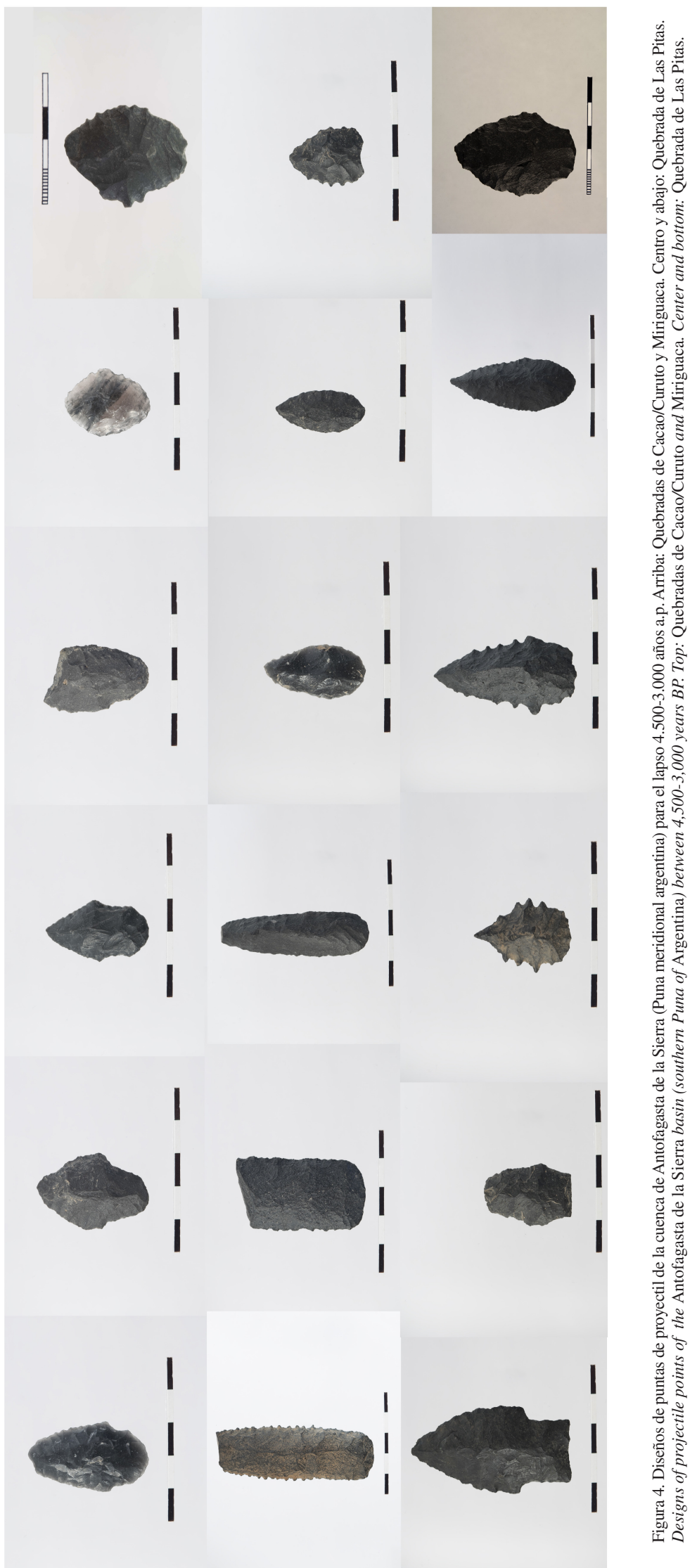


nuevas incorporaciones moldearían sucesivamente las performances culinarias. Esto es lo documentado a través de nuestro análisis de los cambios con continuidades operados durante la TPA antofagasteña en las tradiciones basadas en tubérculos y raíces, granos $\mathrm{y}$ frutos.

Al presente, realizamos un abordaje de la cuisine en la TPA basado en los alimentos vegetales. Por esto, se impone en la agenda futura establecer la participación de las carnes y grasas en las tradiciones culinarias puneñas, dada la concepción de la domesticación animal y la "opción pastoril" como procesos y estrategias "naturales" en la Puna (Aschero y Hocsman 2011; Babot 2016; Olivera 1988). Igualmente, es necesario proveer de mayores evidencias locales sobre los inicios y consolidación de la domesticación de camélidos y el pastoralismo.

Otro desafío futuro es escudriñar la variabilidad de las acciones de los actores, en las prácticas. Ciertas tendencias, como el uso de cultígenos microtérmicos locales y fauna domesticada en todos los sitios residenciales ca. 3.500 a.p., no implican que todos los individuos y grupos de corresidencia cultivaran o que participaran del manejo animal y el pastoreo. Algunos podrían acceder a estos alimentos mediando el comensalismo, la práctica del compartir o el intercambio a escala local, por ejemplo. Los gustos, intereses y habilidades de las personas son disímiles y variables a lo largo de sus historias de vida (Knapp y van Dommelen 2008); resta aproximarse a esta diversidad de posibilidades.

Un aspecto central en el abordaje de la TPA en Antofagasta de la Sierra es el papel de las bases residenciales a cielo abierto, que definen formas novedosas de habitar los lugares y nuevos modos de organizar los espacios intrasitio. Los reparos rocosos siguieron en uso, pero los espacios abiertos adosados fueron empleados recurrentemente. Así, primaron dos modos de habitar, "hacia afuera" de los reparos rocosos y "hacia abajo" en la topografía local, iniciando el uso de explanadas en las Pampas, sobre la cima de los farallones y de sectores aterrazados inmediatos a cursos fluviales.

En los próximos años será preciso identificar sitios residenciales correspondientes al lapso 3.0002.000 a.p., para el que se cuenta únicamente con el alero Punta de la Peña 3A, aunque sitios de otro tipo, como ofrendas, ya han dado cuenta de la continuidad ocupacional (Aschero y Hocsman 2011). Hacia los 3.000 a.p. se produjo un mejoramiento generalizado en la cuenca dado por las condiciones de humedad y una mayor estabilidad ambiental, por lo que corresponde analizar su relación con la reconfiguración de los asentamientos en el área sobre la base de las elecciones operadas en el habitar.

Finalmente, las prácticas de diferenciación social a nivel microrregional están indicadas por la convergencia entre el arte rupestre de la modalidad estilística río Punilla, presente en el nodo del proceso transicional local, y los diseños de puntas de proyectil. Estas últimas constituirían "diacríticos de identidad" en una situación de "coyuntura" particular. La concurrencia de agentes, acciones y factores requiere de mayor estudio, pero las perspectivas son promisorias. El desierto puneño "particionado" por una situación de territorialidad puede ser visto como el lugar donde se expresaban las experiencias sociales vividas diariamente por los actores (Knapp y van Dommelen 2008).

Agradecimientos: A Jorge Martínez por proveer los materiales del sitio Cacao 4. A Lorena Grana por su ayuda inestimable en la elaboración de la Tabla 1 y la Figura 2. A Marcela Alonso (Personal Técnico del ISES, CONICET-UNT) por la realización de las fotos de materiales. A los revisores anónimos por sus comentarios sobre el manuscrito original. Este trabajo se realizó en el marco de los Proyectos PIP 577, dirigido por C. Aschero; PICT 2013-1703, dirigido por S. Hocsman; PIUNT 26/G503, dirigido por M.P. Babot; y SECYT-UNCA 02/G256, dirigido por P.Escola.

\section{Referencias Citadas}

Aldenderfer, M. 1998. Montane Foragers. Asana and the SouthCentral Andean Archaic. University of Iowa Press, Iowa.

Aschero, C.A. 2006. De cazadores y pastores. El arte rupestre de la modalidad río Punilla en Antofagasta de la Sierra y la cuestión de la complejidad en la Puna meridional argentina. En Tramas en la Piedra. Producción y Usos del Arte Rupestre, editado por D. Fiore y M. Podestá, pp. 103-140. WAC, SAA y Asociación de Amigos del INAPL, Buenos Aires.

Aschero, C.A. 2007. Iconos, huancas y complejidad en la Puna Sur Argentina. En Producción y Circulación Prehispánicas de Bienes en el Sur Andino, compilado por A. Nielsen, M. Clara
Rivolta, V. Seldes, M. Vázquez y P. Mercolli, pp.135-165. Editorial Brujas, Córdoba.

Aschero, C.A. 2010. Arqueologías de Puna y Patagonia centromeridional: Comentarios generales y aporte al estudio de los cazadores-recolectores en los proyectos dirigidos desde el IAM (1991-2009). En Rastros en el Camino. Trayectos e Identidades de una Institución. 80 años del Instituto de Arqueología y Museo, editado por C.A. Aschero, P. Arenas y C. Taboada, pp. 257-293. Edunt, San Miguel de Tucumán.

Aschero, C.A. 2016. Cazadores-recolectores, organización social e interacciones a distancia. Un modelado del caso 
Antofagasta de la Sierra (Catamarca, Argentina). Mundo de Antes 10:43-71.

Aschero, C.A., D. Elkin y E. Pintar 1991. Aprovechamiento de recursos faunísticos y producción lítica en el precerámico tardío. Un caso de estudio: Quebrada Seca 3 (Puna Meridional Argentina). Actas XII Congreso Nacional de Arqueología Chilena 2:101-114.

Aschero, C.A. y S. Hocsman 2011. Arqueología de las ocupaciones cazadoras-recolectoras de fines del Holoceno Medio de Antofagasta de la Sierra (Puna Meridional Argentina). Chungara Revista de Antropología 43 Volumen Especial 1:393-411.

Aschero, C.A., L. Manzi y G. Gómez 1993-94. Producción lítica y uso del espacio en el nivel 2b4 de Quebrada Seca 3. Relaciones de la Sociedad Argentina de Antropología XIX:191-214.

Atalay, S. y C.A. Hastorf 2006. Food, meals, and daily activities: Food habitus at Neolithic Çatalhöyük. American Antiquity 71:283-319.

Ayora Díaz, S.I. 2014. El performance de lo yucateco: cocina, tecnología y gusto. Alteridades 24:59-69.

Babot, M.P. 2014. Grinding, processing, settlement and mobility in hunter-gatherers of the Southern Puna of Argentina (ca. 70003200 years AP). En Hunter-gatherers from a High Elevation desert. People of the Salt Puna (Northwest Argentina), editado por E. Pintar, pp. 169-200. BAR International Series, S2641, Archaeopress, Oxford.

Babot, M.P. 2016. Notas sobre la arqueología de las plantas en un desierto de altura. Cadernos do Lepaarq. Textos de Antropologia, Arqueologia e Patrimônio 13:333-365.

Babot, M.P. y S. Hocsman 2016. Quinoa. A millenary grain in Northern Argentina. En Encyclopaedia of The History of Science, Technology, and Medicine in Non-Western Cultures, editado por H. Selin. DOI 10.1007/978-94-007-3934-5_10319-2. Springer, Heidelberg.

Babot, M.P., S. Hocsman, R.E. Piccón Figueroa y M.C. Haros 2012. Recetarios prehispánicos y tradiciones culinarias. Casos de la Puna Argentina. En Las Manos en la Masa. Arqueologías y Antropologías e Historias de la Alimentación en Suramérica, editado por M.P. Babot, M. Marschoff y F. Pazzarelli, pp. 235269. Editorial Corintios, Córdoba.

Barnard, A. 2007. From Mesolithic to Neolithic modes of thought. Going Over. The Mesolithic-Neolithic Transition in North-West Europe, editado por A. Whittle y V. Cummings, pp. 5-19. Proceedings of the British Academy 144. Oxford University Press, Oxford.

Berón, M. 2006. Relaciones interétnicas e identidad social en el registro arqueológico. En Género y Etnicidad en la Arqueología Sudamericana, editado por V.I. Williams y B. Alberti, pp. 119138. Serie Teórica $N^{o}$ 4. FACSO, UNICEN, Olavarría.

Bobillo, F.M. y S. Hocsman 2015. Mucho más que solo aprovisionamiento lítico: actividades en canteras y prácticas sociales en las fuentes de Pampa Oeste, Quebrada Seca y Punta de la Peña (Antofagasta de la Sierra, Catamarca). Revista del Museo de Antropología 8:23-44.

Bourdieu, P. 1997. Razones Prácticas. Sobre la Teoría de la Acción. Anagrama, Barcelona.

Bourdieu, P. 1999. El conocimiento por cuerpos. En Meditaciones Pascalianas, editado por P. Bourdieu pp. 171-214. Editorial Anagrama, Barcelona.

Bourdieu, P. 2007. El Sentido Práctico. Siglo Veintiuno Editores, Buenos Aires.

Boyd, B. 2006. On 'sedentism' in the Later Epipalaeolithic (Natufian) Levant. World Archaeology 38:164-178.

Bronk Ramsey, C. 2013. Recent and planned developments of the Program OxCal. Radiocarbon 55 (2-3):720-730.
Bruno, M.C. 2009. Practice and history in the transition to food production. Current Anthropology 50:703-706.

Bruno, M.C. y W.T. Whitehead 2003. Chenopodium cultivation and Formative Period agriculture at Chiripa, Bolivia. Latin American Antiquity 14:339-355.

Capriles, J.M., S. Calla Maldonado y J. Albarracín-Jordán 2011. Tecnología lítica y estrategias de subsistencia durante los períodos Arcaico y Formativo en el altiplano central, Bolivia. Chungara Revista de Antropología Chilena 43 Volumen Especial Tomo 1:455-468.

Craig, N. 2011. Cultural dynamics, climate, and landscape in the South-Central Andes during the Mid-Late Holocene: A consideration of two socio-natural perspectives. Chungara Revista de Antropología Chilena 43 Volumen Especial Tomo 1:367-391.

Craig, N. 2012. Transiciones del Arcaico Tardío al Formativo Temprano. Una perspectiva desde la arqueología de la unidad doméstica de dos sitios del valle del río llave, cuenca del lago Titicaca. En Arqueología de la Cuenca del Titicaca, Perú, editado por L. Flores Blanco y H. Tantaleán, pp. 41-130. Travaux de l'IFEA, Perú.

Cunningham, P. 2011. Caching your savings: The use of smallscale storage in European prehistory. Journal of Anthropological Archaeology 30:135-144.

Delannoy, J.-J., B. David, J.-M. Geneste, M. Katherine, B. Barker, R.L. Whear y R.G. Gunn 2013. The social construction of caves and rockshelters: Chauvet Cave (France) and Nawarla Gabarnmang (Australia). Antiquity 87:12-29.

Dobres, M. y C. Hoffman 1994. Social agency and the dynamics of prehistoric technology. Journal of Archaeological Method and Theory 1:211-258.

Dobres, M.A. y J.E. Robb 2000a. Agency in Archaeology. Paradigm or platitude? En Agency in Archaeology, editado por M-A. Dobres y J.E. Robb, pp. 3-17. Routledge, Oxon.

Dobres, M.A. y J.E. Robb (eds.) 2000b. Agency in Archaeology. Routledge, Oxon.

Dornan, J.L. 2002. Agency and archaeology: Past, present, and future directions. Journal of Archaeological Method and Theory 9:303-329.

Dudognon, C. y M. Sepúlveda 2016. Rock art of the upper Lluta valley, northernmost of Chile (South Central Andes): A visual approach to socio-economic changes between Archaic and Formative periods (6,000-1,500 years BP). Quaternary International, in press.

Elkin, D. 1996. El uso del recurso fauna por los primeros habitantes de Antofagasta de la Sierra (Puna de Catamarca). Actas del I Congreso de Investigación Social. Región y Sociedad en Latinoamérica. Su problemática en el NOA, pp. 202-209.

Ellen, R. 1994. Modes of subsistence: Hunting and gathering to agriculture and pastoralism. En Companion Encyclopedia of Anthropology. Humanity, Culture and Social Life, editado por T. Ingold, pp. 197-225. Routledge, Oxon.

Escola, P.S., M.G. Aguirre y S. Hocsman 2013. La Gestión de recursos leñosos por cazadores-recolectores transicionales en los sectores intermedios de Antofagasta de La Sierra (Catamarca, Argentina): El caso de Alero Sin Cabeza. Revista Chilena de Antropología 27:67-100.

Escola, P.S., S. Hocsman y M.P. Babot 2016. Moving obsidian: The case of Antofagasta de la Sierra basin (Southern Argentinean Puna) during the late Middle and Late Holocene. Quaternary International 422:109-122.

Finlayson, B. 2010. Agency in the pre-Pottery Neolithic. En Development of Pre-State Communities in the Ancient Near East, editado por A.D. Bolguer y L.C. Maguire, pp. 141-146. Oxbow Books, Oxford. 
Gardner, A. 2011. Paradox and praxis in the archaeology of identity. En Identity Crisis: Archaeological Perspectives on Social Identity, editado por L. Amundsen-Meyer, N. Engel y S. Pickering, pp. 11-26. University of Calgary, Calgary.

Giddens, A. 1995. La Constitución de la Sociedad. Bases para la Teoría de la Estructuración. Ediciones Amorrortu, Buenos Aires.

Grana, L., P. Tchilinguirian, D.E. Olivera, C. Laprida y N.I. Maidana 2016. Síntesis paleoambiental en Antofagasta de la Sierra: heterogeneidad ambiental y ocupaciones humanas en los últimos 7200 años cal AP. Intersecciones en Antropología 4:19-32.

Grana, L., P. Tchilinguirian, S. Hocsman, P.S. Escola y N. Maidana 2016. Paleohydrological changes in highland desert rivers and human occupation, 7000-3000 cal. yr BP, South-Central Andes, Argentina. Geoarchaeology 31:412-433.

Gremillion K.J., L. Barton y D.R. Piperno 2014. Particularism and the retreat from theory in the archaeology of agricultural origins. PNAS 111:6171-6177.

Haas, W.R. y C.V. Llave 2015. Hunter-gatherers on the eve of agriculture: investigations at Soro Mik'aya Patjxa, Lake Titicaca Basin, Peru, 8000-6700 BP. Antiquity 89:1297-1312.

Hamilakis, Y. 2015. Food as sensory experience. En Archaeology of food. An Encyclopedia, editado por K. Bescherer Metheny y M.C. Beaudry, Volumen 2, pp. 205-206. Rowman y Littlefield, Lanham.

Hastorf, C. 2006. Domesticated food and society in early coastal Peru. En Time and Complexity in Historical Ecology Book Subtitle: Studies in the Neotropical Lowlands, editado por W. Balée y C.L. Erickson, pp. 87-126. Columbia University Press, New York.

Hocsman, S. 2002. ¿Cazadores-recolectores complejos en la puna meridional argentina? Entrelazando evidencias del registro arqueológico de la microrregión de Antofagasta de la Sierra (Catamarca). Relaciones de la Sociedad Argentina de Antropología XXVII:193-214

Hocsman, S. 2006. Producción Lítica, Variabilidad y Cambio en Antofagasta de la Sierra -ca.5500-1500 AP-. Tesis para optar al grado de Doctor en Ciencias Naturales, Facultad de Ciencias Naturales y Museo, Universidad Nacional de La Plata, La Plata.

Hocsman, S. 2010. Cambios en las puntas de proyectil durante la transición de cazadores-recolectores a sociedades agro-pastoriles en Antofagasta de la Sierra (Puna argentina). Arqueología 16:5986.

Hocsman, S. 2014. Continuities and discontinuities in the process of transition to food production in Antofagasta de la Sierra (Southern Argentine Puna): the case of flaked stone tools. En Hunter-gatherers from a High-Elevation Desert: People of the Salt Puna Northwest Argentina, editado por E. Pintar, pp. 201-230. BAR International Series, S2641, Archaeopress, Oxford.

Hodder, I. 2017. Things and the Slow Neolithic: the Middle Eastern Transformation. Journal of Archaeological Method and Theory 24:1-23.

Kelly, R. 1995. The Foraging Spectrum: Diversity in HunterGatherer Lifeways. Smithsonian Institution Press, Washington D.C.

Kennett, D.J. y B. Winterhalder (eds.) 2006. Behavioral Ecology and the Transition to Agriculture. University of California Press, Berkeley.

Kintigh, K.W., J.H. Altschul, M.C. Beaudry, R.D. Drennan, A.P. Kinzig, T.A. Kohler, W.F. Limp, H.D.G. Maschner, W.K. Michener, T.R. Pauketat, P. Peregrine, J.A. Sabloff, T.J. Wilkinson, H.T. Wright y M.A. Zeder 2014. Grand challenges for archaeology. PNAS 111:879-880.
Knapp, A.B. y P. van Dommelen 2008. Past practices: rethinking individuals and agents in archaeology. Cambridge Archaeological Journal 18:15-34.

Korstanje, M.A. 2017. Rethinking the role of wild resources in agriculturalist societies: Archives from Rockshelter cases of Northwestern Argentina. En Social Perspectives on Ancient Lives from Paleothnobotanical Data, editado por M.P. Sayre y M.C. Bruno, pp. 77-100. Springer, New York.

Larson, G., D.R. Piperno, R.G. Allaby, M.D. Purugganan, L. Andersson, M. Arroyo-Kalin, L. Barton, C. Climer Vigueira, T. Denham, K. Dobney, A.N. Doust, P. Gepts, M.T.P. Gilbert, K.J. Gremillion, L. Lucas, L. Lukens, F.B. Marshall, K.M. Olsen, J.C. Pires, P.J. Richerson, R. Rubio de Casas, O.I. Sanjur, M.G. Thomas y D.Q. Fuller 2014. Current perspectives and the future of domestication studies. PNAS 111:6139-6146.

López, G.J.E. 2013. Ocupaciones humanas y cambio a lo largo del holoceno en abrigos rocosos de la Puna de Salta, Argentina: Una perspectiva regional. Chungara Revista de Antropología Chilena 45:411-426.

López, G.J.E. y F. Restifo 2012. The Middle Holocene intensification and domestication of camelids in north Argentina, tracked by zooarchaeology and lithics. Antiquity 86:1041-1054.

López, G.J.E. y F. Restifo 2014. Procesos de diversificación, intensificación y domesticación durante el Holoceno en las tierras altas del norte de Argentina y Chile: aportes desde la puna de Salta. Comechingonia 18:95-116.

Lund, J. 2016. Tubérculos y Raíces Útiles de la Puna Meridional Argentina. Un Abordaje desde la Arqueobotánica y la Etnobotánica en Antofagasta de la Sierra (Provincia de Catamarca). Tesina de Grado, Carrera de Arqueología, Facultad de Ciencias Naturales e Instituto Miguel Lillo, Universidad Nacional de Tucumán, Tucumán.

Marks, R. 2007. Los Orígenes del Mundo Moderno. Editorial Crítica, Barcelona.

Marsh, E.J. 2015. The emergence of agropastoralism: Accelerated ecocultural change on the Andean altiplano, $\sim 3540-3120$ cal BP. Environmental Archaeology 20(1):13-29.

Marsh, E.J. 2016. The disappearing desert and the emergence of agropastoralism: An adaptive cycle of rapid change in the mid-Holocene Lake Titicaca Basin (Peru e Bolivia). Quaternary International 422:123-134

McCormac F., A. Hogg, P. Blackwell, C. Buck, T. Higham y P. Reimer 2004. ShCal04 Southern Hemisphere calibration, 0-11.0 Cal Kyr BP. Radiocarbon 46 (3):1087-1092.

Mc Rostie, V. 2014. Arboricultura y silvopastoralismo en el período Formativo (1.400 a.C.-500 d.C.) de la cuenca del Salar de Atacama. Chungara Revista de Antropologia Chilena 46:543-557.

Moreno, E. 2013. Estrategias de caza y paisajes culturales en Antofagasta de la Sierra, Catamarca. Comechingonia 17:95-121.

Muscio, H. 2001. Una Revisión Crítica del Arcaico Surandino. Cátedra de Fundamentos de Prehistoria, Facultad de Filosofía y Letras, UBA, Buenos Aires.

Muscio, H. 2009. El Formativo es una unidad de análisis inadecuada en la arqueología evolutiva del NOA. En Arqueología y Evolución. Teoría, Metodología y Casos de Estudio, editado por G. López y M. Cardillo, pp. 197-213. Editorial sb, Buenos Aires.

Núñez, L., I. Cartajena, C. Carrasco, P. de Souza y M. Grosjean 2006. Emergencia de comunidades pastoralistas formativas en el sureste de la Puna de Atacama. Estudios Atacameños 32:93-117.

Núñez, L., I. Cartajena, C. Carrasco, P. López, P. de Souza, F. Rivera y B.D. Santander 2017. Presencia de un centro ceremonial 
formativo en la circumpuna de Atacama. Chungara Revista de Antropología Chilena 49:3-33.

Núñez, L., V. McRostie e I. Cartajena 2009. Consideraciones sobre la recolección vegetal y la horticultura durante el Formativo Temprano en el sureste de la Cuenca de Atacama. Darwiniana 47:56-75.

Ochoa J. y A. Ladio 2011. Pasado y presente del uso de plantas silvestres con órganos de almacenamiento subterráneos comestibles en la Patagonia. Bonplandia 20(2):265-284

Odell, G. 1994. Assessing Hunter-gatherer Mobility in the Illinois Valley: Exploring Ambiguous Results. En The Organization of North American Prehistoric Chipped Stone Tool Technologies, editado por P. Carr, pp. 70-86. International Monographs in Prehistory, Archaeological Series 7, Ann Harbor.

Olivera, D.E. 1988. La opción productiva: apuntes para el análisis de sistemas adaptativos del Período Formativo del NOA. Precirculados de las ponencias científicas del IX Congreso Nacional de Arqueología Argentina: 83-101.

Olivera, D.E. 1998. Cazadores y pastores tempranos de la Puna Argentina. En Past and Present in Andean Prehistory and Early History. Etnologiska Studier 42:153-180.

Olivera, D.E. y D. Elkin 1994. De cazadores y pastores: el proceso de domesticación de camélidos en la Puna Meridional Argentina. Zooarqueología de Camélidos 1:95-124.

Panter-Brick, C., R.H. Layton y P. Rowley-Conwy 2001. Lines of enquiry. En Hunter-Gatherers: An Interdisciplinary Perspective, editado por C. Panter-Brick, R. Layton y P. Rowley-Conwy, pp. 1-11. Cambridge University Press, Cambridge.

Pearsall, D.M. 2009. Investigating the Transition to Agriculture. Current Anthropology 50(5):609-613.

Perry, L., D.H. Sandweiss, D.R. Piperno, K. Rademaker, M.A. Malpass, A. Umire y P. de la Vera 2006. Early maize agriculture and interzonal interaction in southern Peru. Nature 440(2):76-79.

Pintar, E.L. 1996. Prehistoric Holocene Adaptations to the Salt Puna of Northwest Argentina. PhD Dissertation, Southern Methodist University, Dallas.

Pintar, E.M. y M.F. Rodríguez 2015. Understanding foraging radius and mobility in a high desert. Journal of Archaeological Science 59:142-158.

Price, T.D. y O. Bar-Yosef (eds.) 2011. The Origins of Agriculture: New Data, New Ideas. Current Anthropology 52(4).

Price, T.D. y J. Brown 1985. Aspects of hunter-gatherer complexity. En Prehistoric Hunter-Gatherers: The Emergence of Cultural Complexity, editado por T. Price y J. Brown, pp. 3-20. Academic Press, Orlando.

Ratto, N. 2003. Estrategias de Caza y Propiedades del Registro Arqueológico en la Puna de Chaschuil (Departamento de Tinogasta, Catamarca, Argentina). Tesis para optar al Grado de Doctor en Filosofía y Letras, Facultad de Filosofía y Letras, Universidad de Buenos Aires, Buenos Aires.

Reigadas, M.C. 2001. Variabilidad y Cambio Cultural en el NOA desde los Comienzos de la Domesticación Animal hasta la Consolidación de las Adaptaciones Pastoriles. Tesis para optar al grado de Doctor en Filosofía y Letras, Facultad de Filosofía y Letras, Universidad de Buenos Aires, Buenos Aires.

Robb, J. 2010. Beyond agency. World Archaeology 42:493-520.

Robb, J. 2013. Material Culture, Landscapes of Action, and Emergent Causation. A New Model for the Origins of the European Neolithic. Current Anthropology 54:657-683.

Rodríguez, M.F. 2004. Cambios en el uso de los recursos vegetales durante los distintos momentos del Holoceno en la
Puna Meridional Argentina. Chungara Revista de Antropología Chilena Volumen Especial, Tomo 1:403-413.

Rodríguez, M.F. 2013. Los grupos humanos y las plantas en la Puna meridional argentina: Arqueobotánica de Antofagasta de la Sierra. Intersecciones en Antropología 14:315-339.

Rowley-Conwy, P. 2001. Time, change and the archaeology of hunter-gatherers: how original is the "Original Affluent Society". En Hunter-Gatherers: An Interdisciplinary Perspective, editado por C. Panter-Brick, R. Layton y P. Rowley-Conwy, pp. 39-72. Cambridge University Press, Cambridge.

Rumold, C.U. y M.S. Aldenderfer 2016. Late Archaic-Early Formative period microbotanical evidence for potato at Jiskairumoko in the Titicaca Basin of southern Peru. PNAS 113:13672-13677.

Salazar, D., V. Figueroa, P. Andrade, H. Salinas, L. Olguín, X. Power, S. Rebolledo, S. Parra, H. Orellana y J. Urrea 2015. Cronología y organización económica de las poblaciones arcaicas de la costa de Taltal. Estudios Atacameños 50:7-46.

Sepúlveda, M., T. Saintenoy, L. Cornejo, C. Dudognon, F. Espinoza, Z. Guerrero Bueno y E. Cerrillo-Cuenca 2017. Rock art painting and territoriality in the precordillera of Arica, northern Chile (South Central Andes). Spatial and archaeological approaches for the naturalistic tradition. Quaternary International, en prensa.

Smith, B.D. 2001.Low-level food production. Journal of Archaeological Research 9:1-43.

Smith, C. 2014. Encyclopedia of Global Archaeology. Springer, New York.

Smith, M.L. 2006. The archaeology of food preferences. American Anthropologist 108:480-493.

Snir, A., D. Nadel, I. Groman-Yaroslavski, Y. Melamed, M. Sternberg, O. Bar-Yosef y E. Weiss 2015. The origin of cultivation and Proto-Weeds, long before Neolithic Farming. PLOS ONE 10(7):1-12.

Spadoni, G.N. 2015. Mirada sobre los desechos de talla del sitio Alero Sin Cabeza, Quebrada de Miriguaca (Antofagasta de la Sierra, Catamarca). En Avances en el Estudio de la Transición a la Producción de Alimentos en Antofagasta de la Sierra, editado por L.G. Gonzalez Baroni, F.M. Bobillo, M.G. Aguirre, S. Hocsman y G.N. Spadoni, p. 67. Universidad Nacional de Tucumán E-Book, Tucumán.

Starr, H. 2005. Subsistence: Models and metaphors for the transition to agriculture in Northwestern Europe. Michigan Discussions in Anthropology 15 (1):7-48.

Urquiza, S.V. y C.A. Aschero 2014. Economía animal a lo largo del Holoceno en la Puna Austral argentina: Alero Punta de la Peña 4. Cuadernos del Instituto Nacional de Antropología y Pensamiento Latinoamericano - Series Especiales 2(1):86112.

Whittle, A. y V. Cummings (eds.) 2007. Going Over. The Mesolithic-Neolithic Transition in North-West Europe. Oxford University Press, Oxford.

Winkel, T., M.G. Aguirre, C.M. Arizio, C.A. Aschero, M.P. Babot, L. Benoit, S. Costa-Tártara, M.-P. Dubois, S. Hocsman, R. Joffre, S.M.L. López Campeny, M.M. Manifesto, N. Oliszewski, E. Pintar, S. Zenboudji y H.D. Bertero 2017. Ups and downs in quinoa biodiversity in the Dry Andes: an 18-centuries perspective based on allelic genotyping. Manuscrito en posesión de los autores.

Yacobaccio, H. 1998. The Evolution of South Andean hunter-gatherers. International Union of Prehistoric and Protohistoric Sciences. Proceedings of the XIII Congress 5:389-394 
Yacobaccio, H. 2006. Intensificación económica y complejidad social en cazadores-recolectores surandinos. Boletín de Arqueología PUCP 10:305-320.
Yacobaccio, H., C. Madero, M. Malmierca y M. Reigadas 1997/1998.

Caza, domesticación y pastoreo de camélidos en la Puna Argentina. Relaciones de la Sociedad Argentina de Antropología XXIII:389-421.

\section{Nota}

1 Esta nueva situación plantea preguntas que abren nuevas posibilidades de investigación a futuro, tales como ¿quiénes serían los/las responsables de las innovaciones culinarias?
¿Cuáles serían los procesos sociales de enseñanza/ aprendizaje de las técnicas culinarias y sus circunstancias de uso involucrados en las innovaciones? 